\title{
Interindividual variability of soil arsenic metabolism by human gut microbiota using SHIME model
}

\author{
Naiyi Yin ${ }^{\text {a, b }}$, Huili Du ${ }^{\text {a, b }}$, Pengfei Wang ${ }^{\text {a, b }}$, Xiaolin Cai ${ }^{\text {a, b }}$, Peng Chen ${ }^{\text {b }}$, Guoxin Sun ${ }^{\text {b }}$, \\ Yanshan Cui a, b, * \\ a College of Resources and Environment, University of Chinese Academy of Sciences, Beijing 101408, People's Republic of China \\ ${ }^{\mathrm{b}}$ Research Center for Eco-Environment Sciences, Chinese Academy of Sciences, Beijing 100085, People's Republic of China
}

\section{H I G H L I G H T S}

- Arsenic metabolism between adult and child was significantly different.

- Arsenic methylation ability of adult was 3-folds higher than that of child.

- Child gut microbiota exhibited high As(III) level with high health risk.

- Human gut microbiota from 20 various genera potentially had resistance genes.

\section{A R T I C L E I N F O}

\section{Article history:}

Received 15 March 2017

Received in revised form

17 May 2017

Accepted 5 June 2017

Available online 6 June 2017

Handling Editor: A. Gies

\section{Keywords:}

Arsenic species

Metabolism

Human health

Soil

\begin{abstract}
A B S T R A C T
Arsenic (As) metabolism by human gut microbiota has been evidenced with in vitro experiments from contaminated soils. In this study, the variability in the metabolic potency toward As-contaminated soils and gut microbial diversity were investigated between healthy individuals (Adult versus Child). Arsenic bioaccessibility in the colon phase increased by $1.4-6.8$ and $1.2-8.7$ folds for adult and child, respectively. We found a high degree of As methylation for the colon digests of the adult (mean $2 \mu \mathrm{g}$ methylarsenicals/hr/g biomass), 3-folds higher than that of the child. Besides, arsenite [As(III)] concentration $(1.5-391.3 \mu \mathrm{g} / \mathrm{L})$ for the child was $2-18$ times for the adult. 16S rRNA gene sequencing revealed that human gut microbiota from 20 various genera potentially had resistance genes to reduce and methylate As under conservative statistics. Our results indicated that As metabolism by gut microbiota from adult and child was significantly different. The adult gut microbiota had a great ability of As methylation; the child gut microbiota exhibited high As(III) level, which could encounter high health risk. The identity and activity of arsenic-metabolizing bacteria isolated from human gut and its homologous role in As metabolism need be further explored. This study provides a better understanding of health risk assessment to adults and children upon soil As exposures.
\end{abstract}

๑) 2017 Elsevier Ltd. All rights reserved.

\section{Introduction}

Arsenic (As) is ubiquitous as a toxic contaminant in natural environment and recognized as a class 1 carcinogen to humans (Wang and Mulligan, 2008). Soil is the main source of As exposure by inadvertent oral ingestion, especially through outdoor hand-tomouth behavior by children (Ljung et al., 2006). Recently, in vitro methods with some advantages of ethical, economical, and time,

\footnotetext{
* Corresponding author. College of Resources and Environment, University of Chinese Academy of Sciences, Beijing 101408, People's Republic of China.

E-mail address: cuiyanshan@ucas.ac.cn (Y. Cui).
}

have been recognized an appropriate surrogate to predict in vivo As relative bioavailability (RBA) (Bradham et al., 2011; Juhasz et al., 2014). There are numerous in vitro gastrointestinal methods estimating As bioaccessibility (the fraction of As that is soluble in the gastrointestinal environment of human being and available for absorption) in the gastric and small intestinal phases. The Simulator of Human Intestinal Microbial Ecosystem (SHIME) simulates a dynamic human gastrointestinal tract and cultures the colon microbial community of humans (Molly et al., 1994). The importance of As metabolism has been evidenced with in vitro experiments of human gut microbiota, which can induce As speciation changes and affect As bioaccessibility in contaminated media (Sun et al., 2012; Van de Wiele et al., 2010; Yin et al., 2015). 
Generally, inorganic As (iAs) is the predominant form in the colon. The methylated As species-monomethylarsonic acid $[\mathrm{MMA}(\mathrm{V})]$, dimethylarsinic acid [DMA(V)], and highly toxic monomethylarsonous acid [MMA(III)] have been likewise detected (Van de Wiele et al., 2010; Yin et al., 2015; Yu et al., 2016). Rubin et al. (2014) described microbial thiolation leading to monomethylmonothioarsonic acid [MMMTA(V)]. In addition, recent studies on human urine analysis revealed some sulfur-containing methylated As metabolites, dimethylmonothioarsinic acid [DMMTA(V)], and dimethyldithioarsinic acid [DMDTA(V)] formed through As thiolation (Kubachka et al., 2009; Naranmandura et al., 2007). Nevertheless, human gut microbiota can actively volatilize As with the formation of highly toxic $\mathrm{AsH}_{3}$ (arsine) (Michalke et al., 2008). In short, speciation analysis must be considered as an essential part of human health risk assessment, especially with respect to As toxicity largely determined by its species (Sun et al., 2014). Arsenic methylation was initially considered a detoxification process, but the formation of some methylated toxic As metabolites has forced researchers to reconsider the methylation process. Furthermore, As metabolism by human gut microbiota and intestinal absorption of these As metabolites should be concurrent processes. Intestinal absorption of different As standard species or metabolites is examined using in vitro studies with the Caco-2 human cell line of human colon carcinoma (Hinrichsen et al., 2015; Yin et al., 2017). In short, methylated trivalent arsenicals display a higher transport across epithelial cells in comparison with inorganic arsenic and the methylated pentavalent species. Besides, some thiolated methylarsenicals [DMMTA(V) and MMMTA(V)] are efficiently absorbed across Caco-2 cells.

The gut microbiota covers a large set of variable genes in numerous bacterial species with significant functions, which plays a number of important roles in human health. The colon represents a highly reducing environment, and harbors a vast (populated by a total of $10^{14}$ bacteria) and incredibly diverse microbial community, which reveals the metabolic potency toward xenobiotics (Schlebusch et al., 2015; Van de Wiele et al., 2010). However, the structure and activity of human gut microbiota from different individuals varies distinctly with diet, gender, and region (Arumugam et al., 2011; David et al., 2014; Greenblum et al., 2015); accordingly, variability in the diversity of human gut microbiota has been examined in populations with a wide range of ages. To date, limited efforts have been made to investigate differences between individuals regarding As metabolism by gut microbiota. When we conversely consider As exposure linked to a number of diseases, Lu et al. (2014) found that As exposure alters the gut microbial community at the abundance level, which substantially perturbs its metabolic profiles at the function level through the integrated metagenomics analysis.

In the present study, high performance liquid chromatographyinductively coupled plasma mass spectrometry (HPLC-ICP-MS) was used to determine As metabolites, and to further evaluate variability in the metabolic potency toward soil As of gut microbiota from two healthy individuals (adult and child). Besides, we applied the 16S rRNA gene sequencing to characterize interindividual variability in gut microbial community. This study provides a better understanding of evaluating health risk to adults and children associated with soil As exposures, and can be as a reference to formulate related health risk policies.

\section{Materials and methods}

\subsection{Arsenic-contaminated soils}

Eight soils collected from a range of mining and farmland locations in China, covered a range of soil physicochemical properties and different concentrations of total As (Table 1). Airdried soils were sieved to a particle size fraction of $<250 \mu \mathrm{m}$ that is most likely to stick to the hands of exposed humans. Soil pH was determined in water extracts (1:2.5 soil: deionized water) after $0.5 \mathrm{~h}$ of equilibration. Organic matter (OM) content was analyzed by UV/visible spectrophotometry after using acid dichromate oxidation method. A laser particle size analyser (Mastersizer, 2000; Malvern, U.K.) was used to obtain soil clay content (soil organic matter dislodged by $\mathrm{H}_{2} \mathrm{O}_{2}$ ). Amorphous iron and manganese oxides ( $\mathrm{Fe}^{\mathrm{AO}}$, and $\mathrm{Mn}^{\mathrm{AO}}$ ) were extracted using $0.2 \mathrm{M}$ acid ammonium oxalate. After microwave digestion (CEM MARS6) using a mixture of concentrated $\mathrm{HNO}_{3}, \mathrm{H}_{2} \mathrm{O}_{2}$, and $\mathrm{HF}$ (5:3:2), total As and other metals concentrations were determined by inductively coupled plasma-optical emission spectroscopy (ICP-OES, Optima 7300V, PerkinElmer, U.S.) or inductively coupled plasma mass spectrometry (ICP-MS, 7500a, Agilent, U.S.). In the digestion process, blank sample and soil reference material GSS-5 (National Institute of Metrology, China) were included to ensure the internal quality assurance/quality control $(\mathrm{QA} / \mathrm{QC})$, whereas As recovery was $103.0 \pm 3.2 \%(n=6)$.

\subsection{Dynamic SHIME}

The in vitro colon microbial community utilized in the experiments was cultured and maintained in a modified SHIME, simulating the stomach, small intestine, ascending colon, transverse colon, and descending colon. Generally, fresh fecal microorganisms were obtained from a 28-year-old and a 6-year-old Chinese healthy male volunteer (no history of antibiotic treatment in the six months before this study), and separately inoculated into three colon compartments. Briefly, feed solution detailed in Yin et al. (2016), was added three times per day to provide digested nutrition for the colon microorganisms. After 3-4 weeks of adaptation, stable microbial communities were obtained in the colon microorganisms. The distal colon microbial fermentation activity (short chain fatty acid production and ammonium production) and community composition are investigated to be consistent with that of previous SHIME runs and an in vivo situation (Molly et al., 1994; Yin et al., 2015).

\subsection{Arsenic metabolism of colon microbiota from contaminated soils}

Arsenic bioaccessibility and its speciation in eight contaminated soils have been investigated through the combination of two in vitro methods, including the physiologically based extraction test (PBET) (Ruby et al., 1996) and the Unified Bioaccessibility Research Group of Europe (BARGE) method (UBM) (Wragg et al., 2011) with SHIME to subsequently simulate stomach, small intestine, and colon conditions, respectively. Briefly, soils $(0.3 \mathrm{~g})$ in triplicate were added to polypropylene conical centrifuge tubes $(50 \mathrm{~mL})$ with the gastric and small intestinal solutions $(30 \mathrm{~mL})$ at a soil/solution $(\mathrm{s} / \mathrm{s})$ ratio of $1: 100$. Following the small intestinal phase, these digests were transferred into $100 \mathrm{~mL}$ anaerobic serum bottles with $30 \mathrm{~mL}$ of colon solution from the descending colon compartment of the dynamic SHIME system at a double ratio (s/s) of the small intestinal phase. To obtain anaerobic conditions, the bottles were capped with butyl rubber stoppers and immediately flushed with nitrogen gas for 20-30 min. The digests were shaken at $150 \mathrm{rpm}$ and incubated at $37^{\circ} \mathrm{C}$ for $48 \mathrm{~h}$.

All samples passed through $0.45 \mu \mathrm{m}$ filter were subsequently stored at $-80^{\circ} \mathrm{C}$ until analysis. Arsenic concentrations in the small intestinal and colon (12 and $24 \mathrm{~h}$ ) digests, were quantified using ICP-MS (diluted with $3 \% \mathrm{HNO}_{3}$ ), while the average recovery of check samples $\left(20 \mu \mathrm{g} \mathrm{L}^{-1}\right)$ was $99.3 \%(94.5-100.6 \%, n=15)$ during 
Table 1

Physicochemical properties of soils $(n=3)$ used in this study.

\begin{tabular}{|c|c|c|c|c|c|c|c|c|c|c|}
\hline \multirow[t]{2}{*}{ ID } & \multirow[t]{2}{*}{ Location (Province) } & \multirow[t]{2}{*}{ Type } & \multirow{2}{*}{$\frac{\text { As }}{\left(\mathrm{mg} \mathrm{kg}^{-1}\right)}$} & \multirow{2}{*}{$\frac{\mathrm{OC}}{(\%)}$} & \multirow[t]{2}{*}{$\mathrm{pH}$} & \multirow{2}{*}{$\frac{\text { Clay }}{(\%)}$} & $\mathrm{Fe}^{\mathrm{AO}}$ & $\mathrm{Mn}^{\mathrm{AO}}$ & \multirow[t]{2}{*}{$\mathrm{Fe}$} & \multirow[t]{2}{*}{ Mn } \\
\hline & & & & & & & \multicolumn{2}{|c|}{$\left(\mathrm{g} \mathrm{kg}^{-1}\right)$} & & \\
\hline S1 & Guangxi & Mining & 3225.6 & 3.9 & 2.4 & 2.2 & 70.4 & 0.1 & 129.4 & 0.6 \\
\hline S2 & Hunan & Farmland & 419.9 & 4.0 & 7.3 & 20.9 & 3.2 & 0.1 & 25.9 & 0.5 \\
\hline S3 & Hunan & Mining & 287.3 & 5.2 & 7.3 & 1.0 & 8.2 & 0.6 & 36.8 & 0.7 \\
\hline S4 & Hunan & Mining & 160.7 & 0.9 & 5.8 & 31.3 & 0.8 & 0.4 & 35.5 & 0.5 \\
\hline S5 & Jiangxi & Farming & 139.5 & 1.9 & 6.1 & 4.7 & 3.4 & 0.2 & 26.0 & 0.6 \\
\hline S6 & Inner Monglia & Mining & 110.9 & 1.7 & 7.4 & 0.8 & 1.9 & 0.5 & 21.1 & 1.5 \\
\hline S7 & Guizhou & Smelting & 109.3 & 5.6 & 7.9 & 12.7 & 16.3 & 1.2 & 50.9 & 1.4 \\
\hline S8 & Hunan & Mining & 80.0 & 3.7 & 7.2 & 1.7 & 4.1 & 0.4 & 32.2 & 0.6 \\
\hline
\end{tabular}

${ }^{\mathrm{AO}}$ : amorphous Fe, and Mn oxides.

the measurement process. Arsenic speciation analysis was performed using HPLC-ICP-MS (diluted with $20 \mathrm{mmol} / \mathrm{L}\left(\mathrm{NH}_{4}\right)_{2} \mathrm{CO}_{3}$ at $\mathrm{pH}$ 9.0), and the sum of all chromatographic As species detected in the colon digests ( $48 \mathrm{~h}$ ) was used to determine As bioaccessibility. Furthermore, the validation of chromatographic recovery was previously described (Yin et al., 2016).

\subsection{S rRNA gene sequencing and data analysis}

Total DNA of the descending colon microbiota from SHIME reactor of two volunteers was isolated using the FastDNA SPIN Kit for Soil (MP Biomedicals, USA) according to the manufacturer's instructions. DNA was quantified by NanoDropND-2000 (NanoDrop Technologies, Wilmington, DE) and stored at $-80{ }^{\circ} \mathrm{C}$ for further analysis. Subsequently, the genomic DNA with the barcode was amplified using universal primers $515 \mathrm{~F}$ (GTGCCAGCMGCCGCGGTAA) and 907R (CCGTCAATTCCTTTGAGTTT) to target the V4-V5 regions of $16 \mathrm{~S}$ rRNA gene. All PCR reactions were carried out with Phusion ${ }^{\circledR}$ High-Fidelity PCR Master Mix (New England Biolabs). PCR products were mixed in equidensity ratios, and subsequently purified with Qiagen Gel Extraction Kit (Qiagen, Germany). Sequencing libraries of individual samples were constructed, and sequenced on the Illumina Hiseq 2500 platform (Illumina, San Diego, CA) to generate $250 \mathrm{bp}$ pair-ended reads.

Raw Illumina fastq files were demultiplexed, quality-filtered and analyzed using Quantitative Insights into Microbial Ecology (QIIME v1.7.0) software (http://qiime.org). Reads were filtered under specific default parameters, in which reads were discarded with a minimum Phred quality score of $<20$ or an incorrect sample barcode. In addition, reads with three consecutive low-quality bases were truncated. After quality filtering, chimera sequences were removed using UCHIME algorithm, and finally the effective reads were obtained. Operational taxonomic units (OTUs) were assigned using the Uparse software (http://drive5.com/uparse/), with a threshold of $97 \%$ sequence similarity. OTU representative sequences were classified taxonomically using the Ribosomal Database Project (RDP) classifier with a 0.80 confidence threshold, in which the Greengenes 16S rRNA gene database (97\% sequence similarity) was used.

\subsection{Statistic analysis}

One-way ANOVA based on the least significant difference was performed to determine significant differences in the As bioaccessibility values for each soil using SPSS 20.0 (IBM), and the same letter indicated that data are not significantly different $(P>0.05)$.

\section{Results}

\subsection{Arsenic bioaccessibility in contaminated soils}

Table 2 compared As bioaccessibility values in the small intestinal phases for the 8 soils, and As bioaccessibility (5.5-25.0\%) for UBM was higher than these values (2.9-19.4\%) of PBET, similar to some previous reports (Fig. S1). Following transition from the small intestinal to the colon phase, significant differences $(P<0.05)$ were observed in As bioaccessibility for all soils. For SHIME with adult gut microbiota, As bioaccessibility increased by $1.4-6.8$ and $1.6-4.3$ folds in the colon phase of PBET/UBM-SHIME (Adult) (PA/UA-C); accordingly, for the PBET/UBM-SHIME (Child) methods (PC/UC) the similar increase in As bioaccessibility was observed by $1.2-8.7$ and 1.4-3.9 folds in the colon phase. We made a preliminary observation on the As dynamic dissolution during simulating colon digestion, which revealed that As bioaccessibility kept relatively steady state after $12 \mathrm{~h}$ for most soils. Previous studies have reported an increase in As bioaccessibility following inclusion of an colon phase (Laird et al., 2007; Yin et al., 2015); in contrast, reduction in As bioaccessibility following modification of the small intestinal to colon phase conditions has previously been shown using IVG combined with SHIME (Van de Wiele et al., 2010). Besides, As bioaccessibility in the colon phase of PA and UA methods was either congruent with or higher than that in PC/UC-C for all soils except soil 1 where PC value exceeded the corresponding PA value. Interestingly, dissolved As levels in the colon digests correlated with those of dissolved Fe $\left(R^{2}=0.56, P<0.01\right)$ and $\mathrm{Mn}\left(R^{2}=-0.49\right.$, $P<0.01$ ) (Table S1).

\subsection{Arsenic speciation and its transformation in the colon: as reduction and methylation}

The most important part of this study consisted of As speciation analysis and its transformation in the colon digests. To our knowledge, this is the first description of variability in the metabolic potency of gut microbiota toward soil As in an oral exposure pathway between two healthy individuals (Adult versus Child). In the colon digests, the presence of $\mathrm{As}(\mathrm{III}), \operatorname{MMA}(\mathrm{V}), \mathrm{DMA}(\mathrm{V})$, and $\mathrm{As}(\mathrm{V})$ was detected as reported (Table 2 and Fig. S2). The predominant As form was As(V) exceeding 80\% (80.0-98.7\%) for all soils, with the exception of $74.2 \%$ (soil 4) and 68.4\% (soil 6) for PBETSHIME (Child) method. As previously reported, As(III) concentration was low and can be appropriately neglected in the small intestinal phase. The highest concentration of $\mathrm{As}(\mathrm{III})$ was up to $391.3 \mu \mathrm{g} / \mathrm{L}$ for PBET-SHIME (Child) colon digests of soil 1 . In most cases, As(III) concentrations were under $30 \mu \mathrm{g} / \mathrm{L}$. Interestingly, As(III) concentrations for the colon digests of the adult were lower than that of the child for all soils except soil 3 in UBM-SHIME method where values were opposite. 
Table 2

Arsenic bioaccessibility (BA), percentages of $\mathrm{As}(\mathrm{III})$, methylated As, and $\mathrm{As}(\mathrm{V})$, and methylation rate by colon microorganisms in colon digests $(n=3)$.

\begin{tabular}{|c|c|c|c|c|c|c|c|c|}
\hline \multirow[t]{3}{*}{ Sample } & \multirow[t]{3}{*}{ Method } & \multirow{3}{*}{$\frac{\text { Intestine }}{\mathrm{BA}}$} & \multicolumn{6}{|l|}{ Colon } \\
\hline & & & \multirow{2}{*}{$\frac{\mathrm{BA}}{(\%)}$} & \multirow{2}{*}{$\frac{\mathrm{As}(\mathrm{V})}{(\%)}$} & \multirow{2}{*}{$\frac{\mathrm{As}(\mathrm{III})}{(\%)}$} & \multicolumn{2}{|c|}{ Methylated As } & \multirow{2}{*}{$\frac{\text { Methylation rate }^{\mathrm{b}}}{(\mu \mathrm{g} / \mathrm{hr} / \mathrm{g} \text { biomass })}$} \\
\hline & & & & & & $(\mu \mathrm{g} / \mathrm{L})$ & $(\%)$ & \\
\hline \multicolumn{9}{|l|}{ A } \\
\hline \multirow[t]{4}{*}{ S1 } & $\mathrm{PA}^{\mathrm{a}}$ & $2.9 \pm 0.1 \mathrm{~d}$ & $19.5 \pm 1.2 b c$ & 97.0 & 0.7 & $73.2 \pm 9.4$ & 2.3 & $3.2 \pm 0.4$ \\
\hline & $\mathrm{PC}$ & & $25.0 \pm 1.3 a$ & 90.3 & 9.7 & & & \\
\hline & UA & $5.5 \pm 0.4 d$ & $23.7 \pm 2.0 \mathrm{ab}$ & 96.2 & 0.8 & $116.8 \pm 5.8$ & 3.0 & $5.2 \pm 0.3$ \\
\hline & UC & & $17.9 \pm 1.3 c$ & 94.6 & 5.4 & & & \\
\hline \multirow[t]{4}{*}{ S2 } & PA & $19.4 \pm 0.01 \mathrm{e}$ & $49.6 \pm 1.9 b$ & 87.4 & 1.0 & $120.5 \pm 1.9$ & 11.6 & $5.3 \pm 0.1$ \\
\hline & PC & & $41.7 \pm 2.1 c$ & 85.3 & 7.2 & $66.1 \pm 1.8$ & 7.5 & $2.1 \pm 0.1$ \\
\hline & UA & $25.0 \pm 1.3 d$ & $59.1 \pm 1.7 a$ & 87.1 & 0.7 & $155.6 \pm 3.9$ & 12.2 & $6.9 \pm 0.2$ \\
\hline & UC & & $53.0 \pm 0.1 b$ & 81.7 & 8.8 & $108.5 \pm 5.1$ & 9.5 & $3.4 \pm 0.2$ \\
\hline \multirow[t]{4}{*}{ S3 } & PA & $19.4 \pm 1.6 c$ & $29.0 \pm 0.2 b$ & 94.0 & 5.5 & $2.0 \pm 0.3$ & 0.5 & $0.1 \pm 0.01$ \\
\hline & PC & & $23.0 \pm 2.4 c$ & 84.6 & 15.4 & & & \\
\hline & UA & $22.3 \pm 0.8 c$ & $43.0 \pm 1.0 a$ & 95.2 & 3.0 & $11.4 \pm 0.8$ & 1.8 & $0.5 \pm 0.04$ \\
\hline & UC & & $32.1 \pm 0.1 b$ & 97.8 & 2.2 & & & \\
\hline \multirow[t]{4}{*}{ S4 } & PA & $5.1 \pm 0.8 \mathrm{e}$ & $31.6 \pm 1.0 \mathrm{~b}$ & 81.5 & 2.3 & $41.2 \pm 2.6$ & 16.2 & $1.8 \pm 0.1$ \\
\hline & PC & & $23.6 \pm 1.5 c$ & 74.3 & 14.9 & $20.5 \pm 0.1$ & 10.8 & $0.6 \pm \mathrm{M}^{\mathrm{c}}$ \\
\hline & UA & $13.0 \pm 1.0 \mathrm{~d}$ & $39.6 \pm 1.8 \mathrm{a}$ & 84.5 & 3.5 & $39.1 \pm 0.3$ & 12.0 & $1.7 \pm 0.01$ \\
\hline & UC & & $39.9 \pm 0.8 a$ & 80.7 & 14.5 & $15.9 \pm 1.6$ & 4.8 & $0.5 \pm 0.05$ \\
\hline \multicolumn{9}{|c|}{ - - } \\
\hline \multirow[t]{4}{*}{ S5 } & $\mathrm{PA}^{\mathrm{a}}$ & $11.3 \pm 2.2 b c$ & $16.1 \pm 0.2 \mathrm{a}$ & 91.1 & 7.5 & $1.2 \pm 0.1$ & 1.4 & $0.06 \pm 0.01$ \\
\hline & PC & & $17.2 \pm 0.1 \mathrm{a}$ & 68.4 & 31.6 & & & \\
\hline & UA & $9.2 \pm 0.9 c$ & $14.7 \pm 0.9 \mathrm{ab}$ & 94.0 & 2.7 & $2.7 \pm 0.2$ & 3.3 & $0.09 \pm \mathrm{M}^{\mathrm{c}}$ \\
\hline & UC & & $13.2 \pm 1.0 \mathrm{ab}$ & 98.0 & 2.0 & & & \\
\hline \multirow[t]{4}{*}{ S6 } & PA & $5.8 \pm 1.0 \mathrm{c}$ & $36.1 \pm 1.0 a$ & 82.2 & 0.7 & $42.9 \pm 0.6$ & 17.1 & $1.9 \pm 0.03$ \\
\hline & PC & & $27.8 \pm 1.4 b$ & 84.7 & 2.8 & $24.3 \pm 3.6$ & 12.5 & $0.8 \pm 0.1$ \\
\hline & UA & $9.6 \pm 0.6 c$ & $36.5 \pm 0.1 \mathrm{a}$ & 85.3 & 0.8 & $36.3 \pm 1.3$ & 13.9 & $1.6 \pm 0.06$ \\
\hline & UC & & $37.3 \pm 2.8 a$ & 85.2 & 5.0 & $26.1 \pm 0.1$ & 9.8 & $0.8 \pm \mathrm{M}$ \\
\hline \multirow[t]{4}{*}{ S7 } & PA & $5.5 \pm 0.1 \mathrm{e}$ & $15.4 \pm 0.6 b$ & 89.9 & 0.7 & $7.9 \pm 1.0$ & 9.4 & $0.3 \pm 0.05$ \\
\hline & PC & & $11.5 \pm 0.6 c$ & 93.3 & 6.7 & & & \\
\hline & UA & $9.0 \pm 0.1 d$ & $21.8 \pm 0.1 \mathrm{a}$ & 97.4 & 0.5 & $2.6 \pm 0.1$ & 2.1 & $0.1 \pm M$ \\
\hline & UC & & $20.6 \pm 0.7 a$ & 98.7 & 1.3 & & & \\
\hline \multirow[t]{4}{*}{ S8 } & PA & $17.0 \pm 1.9 \mathrm{~d}$ & $52.5 \pm 1.5 a$ & 86.7 & 1.3 & $25.1 \pm 0.1$ & 12.0 & $1.1 \pm \mathrm{M}$ \\
\hline & PC & & $39.7 \pm 1.7 b$ & 80.0 & 13.3 & $10.7 \pm 0.2$ & 6.7 & $0.3 \pm 0.01$ \\
\hline & UA & $23.5 \pm 0.2 c$ & $55.9 \pm 0.5 a$ & 92.7 & 3.7 & $8.3 \pm 1.1$ & 3.6 & $0.4 \pm 0.05$ \\
\hline & UC & & $51.5 \pm 1.5 a$ & 95.7 & 4.3 & & & \\
\hline
\end{tabular}

${ }^{a}$ PA/UA and PC/UC: PBET/UBM-SHIME (Adult/Child).

b Calculated by dividing MMA $(\mathrm{V})$ and $\mathrm{DMA}(\mathrm{V})$ in the colon digests by the initial biomass concentration and time (48 $\mathrm{h})$.

${ }^{c}$ M: SD values $<0.01$. Means marked with the same letter indicate that data are not significantly different $(P>0.05)$.

We observed significant As methylation upon colon incubation of the eight contaminated soils, and the percentages and concentrations of organic As [MMA(V) and DMA(V)] also differed (Fig. S2). For colon digests of the PA, UA, and PC, UC methods, the methylation percentages were $0.5-17.1 \%, 1.8-13.9 \%$, and $6.7-12.5 \%$, 4.8-9.8\%, respectively. In comparison, the concentrations of iAs species exceeded observably that of organic As in colon digests; accordingly, MMA(V) and $\mathrm{DMA}(\mathrm{V})$ concentrations deserved more attention. The UBM-SHIME (Adult) colon digest of soil 2 displayed a higher As methylation with $\operatorname{MMA}(\mathrm{V})(17.8 \mu \mathrm{g} / \mathrm{L})$ and $\mathrm{DMA}(\mathrm{V})$ $(137.8 \mu \mathrm{g} / \mathrm{L})$, whereas only $1.2-2.7 \mu \mathrm{g} / \mathrm{L}$ of $\mathrm{DMA}(\mathrm{V})$ was detected in the colon digests (Child) of soil 3, 6, and 7. In some cases for the child, no methylated As species were detected in the colon digests (Fig. S2). Interestingly, the sum of the concentrations of MMA(V) and $\mathrm{DMA}(\mathrm{V})$ in the colon digests of the adult was higher than that of the child for all soils. For soils 2, 4, 5, and 8, the higher concentrations of organic As was MMA(V) (Child) and DMA(V) (Adult) in the presence of As methylation simultaneously for two individuals. Summarizing changes of the in vitro As speciation, we calculated the As methylation rates by taking into account the colon incubation $48 \mathrm{~h}$ and As concentrations. The methylation rate (mean value of $2 \mu \mathrm{g}$ methylarsenicals/hr/g biomass) for the colon digests of the adult was $2.0-3.5(2.7 \pm 0.6)$ times than that for the child (Table 2$)$, which is calculated by dividing $\operatorname{MMA}(\mathrm{V})$ and $\mathrm{DMA}(\mathrm{V})$ in the colon digests by the initial biomass concentration and the incubation time $(48 \mathrm{~h})$.

\subsection{Difference in microbial communities between individuals}

The taxonomic assignment of $16 \mathrm{~S}$ rRNA sequencing data was achieved at different levels, including kingdom, phylum, class, order, family and genus. Fig. 1 shows the identified gut bacteria assigned at the genus level from 16S rRNA sequencing reads (each color represents an individual bacterial genus). In terms of the assignment at the phylum level (Fig. S3), Bacteroidetes dominated the microbial communities, being much more abundant than Firmicutes, approximate to previous reports on several phyla in the SHIME (Van den Abbeele et al., 2010). The comparison on gut microbiota at the genus level between an adult and a child, observed that the predominant genus was Bacteroides (Arumugam et al., 2011). Other abundant genera respectively were EscherichiaShigella (18.5\%), Akkermansia (11.9\%) for an adult and Desulfovibrio (13.2\%), Akkermansia (10.6\%) for a child. Parabacteroides (8.2\%), Cloacibacillus (5.0\%), Alistipes (2.4\%) in the adult gut microbiota displayed higher abundances; accordingly, the percentages of Pyramidobacter (6.8\%), Providencia (5.1\%), Klebsiella (4.6\%), Lachnoclostridium (2.9\%) for the child exceeded that of the adult.

\section{Discussion}

The data convinced us that the human gut microbiota had the potency to enhance As solubility from soils and As release ability of adult gut microbiota was stronger. The adsorption affinity of As(III) 

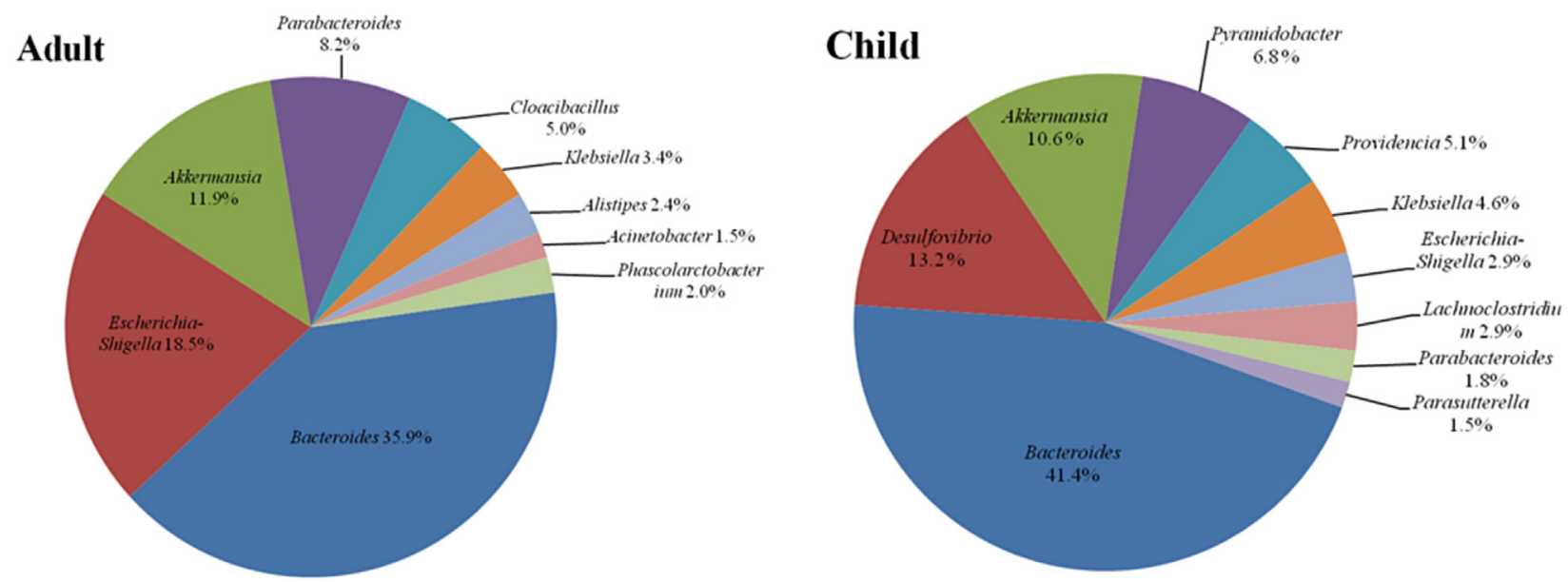

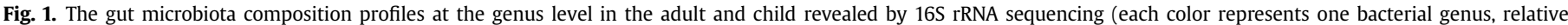
abundance $>1 \%, n=3$ ). (For interpretation of the references to colour in this figure legend, the reader is referred to the web version of this article.)

to metal minerals was weaker than that of $\mathrm{As}(\mathrm{V})$; as a consequence, microbial reduction of $\mathrm{As}(\mathrm{V})$ enhanced As mobility. The dissolution of amorphous $\mathrm{Fe}$ oxides resulted from $\mathrm{Fe}(\mathrm{III})$ reduction in the presence of $\mathrm{Fe}(\mathrm{III})$-reducing bacteria, played an important role in the enhancement of As solubilisation (Islam et al., 2004; Tian et al., 2015). Another contrasting consequence was As sequestration associated with the formation of secondary Fe-minerals during microbial Fe(III) reduction (Jiang et al., 2013; Muehe et al., 2013). In addition, Mn oxides also played a small, but influential role in the inhibition of As solubilisation, which had the potency to oxidize As(III) and sequester As (Wu et al., 2015; Ying et al., 2011). Therefore, the increase in As bioaccessibility can simultaneously be controlled by As liberation and transformation, reductive dissolution of $\mathrm{Fe}(\mathrm{III})$, and $\mathrm{As}(\mathrm{III})$ oxidation of Mn oxides. Besides, the validation of in vivo-in vitro relationships for better predicting As RBA for human health has been reported previously (Denys et al., 2012; Juhasz et al., 2011, 2014, 2015). It is essential to validate in vitro methods combined with SHIME to assess As bioaccessibility (colon phase) against in vivo data in future research.

Arsenic metabolism is a complicated process and includes a series of oxidation, reduction, methylation, and other reactions. Zhu et al. (2014) summarized the As species and their biotransformation with known enzymes for biotransformation and representative protein structures. Summarizing the in vitro As speciation changes, the adult gut microbiota had a great ability to induce As liberation from soils and $\mathrm{As}(\mathrm{V})$ transformation ended up with high levels of $\mathrm{DMA}(\mathrm{V})$; nevertheless, the child can encounter higher health risk for the colon digests with a large number of As(III). As previously described by in vitro studies with human gut microbiota, different extents of As methylation was analogously observed (Van de Wiele et al., 2010; Yin et al., 2015). Taking into account the formation of some methylated and thiolated arsenicals with high toxicity, we need reconsider As methylation, originally considered a detoxification process. Based on these known data about As methylation in the presence of the complicated soil matrix, some soil parameters play key factors. The reactive iron oxide content or some toxic elements in soils can affect colon microorganisms (Van de Wiele et al., 2010). Yu et al. (2016) found that Fe could play an important role in mediating As methylation by human gut microbiota.

High-throughput 16S rRNA gene sequencing was used to analyse the descending colon microbiota in this SHIME system from two healthy male volunteers ( 6 and 28 years). Here we preliminarily observed interindividual variability in gut microbial community. When children after 2 years of age, the gastrointestinal conditions and transit tends to stable, and the gut microbiota of children is generally the same as adult (Bowles et al., 2010; Palmer et al., 2007). The data clearly revealed the variation in the gut microbiota composition of two individuals, which could affect As reduction, methylation, and other reactions. The enzymes of reductase and methyltransferase are known to participate in the As reduction and methylation pathways (Zhu et al., 2014). Both the respiration and detoxification mechanism facilitate microbial $\mathrm{As}(\mathrm{V})$ reduction. Anaerobic dissimilatory $\mathrm{As}(\mathrm{V})$ reduction is catalyzed by arsenate respiratory reductases, consisting of ArrA and ArrB. In comparison with the respiration using arsenate as a terminal electron acceptor, detoxification is also an efficient $\mathrm{As}(\mathrm{V})$-reducing mechanism; reductase enzymes named ArsC, use glutaredoxin and glutathione as electron donors. Arsenic methylation is catalyzed by a family of As(III) S-adenosylmethionine (SAM) methyltransferase enzymes (ArsM), and SAM is the methyl donor transferred to As(III) for the formation of mono-, di-, and trimethylated arsenicals (Chen et al., 2013).

Many microorganisms with arrA, arsB, arsC, and arsM genes isolated from water, soil, sediment or other media, have the biotransformation potency to reduce $\mathrm{As}(\mathrm{V})$ and methylate $\mathrm{As}(\mathrm{III})$. In our study, based on 16S rRNA sequencing data of human gut microbiota, bacterial species from 20 various genera with potential As resistance genes were observed (Table S2) according to previous reports. There are a number of previously described $\mathrm{As}(\mathrm{V})$-reducing bacteria, such as Clostridium, Sulfurospirillum, Pseudomonas, Shewanella, Escherichia, Bacillus, etc (Bennett et al., 2011; Guo et al., 2015; Zobrist et al., 2000). Nevertheless, some species from the same genera have As(III) SAM methyltransferases, which can convert As(III) into methylated species that eventually end up even as small amounts of TMAs(V)O and volatile trimethylarsine (Chen and Rosen, 2016; Qin et al., 2006; Stolz et al., 2006; Zhang et al., 2015). The presence of arsM genes in certain species of Desulfovibrio, Bacteroides, Alcaligenes have been reported previously (Huang, 2014; Lin et al., 2006). The As-gut microbiota interactions are significant to better understand the roles of microorganisms in As metabolism. Interestingly, sulfate-reducing and $\mathrm{Fe}(\mathrm{III})$-reducing bacteria are versatile like Shewanella, Sulfurospirillum, and Desulfovibrio, which can be capable of As(III) oxidation, dissimilatory $\mathrm{As}(\mathrm{V})$ reduction, or $\mathrm{As}(\mathrm{III})$ methylation, and even respire selenate, nitrate, and nitrite (Islam et al., 2004; Oremland and Stolz, 2003, 2005). In particular, Fe(III)-reducing bacteria can concurrently affect reduction and release of $\mathrm{Fe}(\mathrm{III})$ and $\mathrm{As}(\mathrm{V})$. 
In consideration of culture characteristics (cost and time) in SHIME model, it is a little hard for a large number of individuals, and we investigated the variability in As metabolism by gut microbiota from two individuals. Human gut microbiota are known for their high interindividual variability. Considering some factors of the age, diet, and disease, the microbial community is in constant changes, and presystemic metabolism should be under corresponding variation in an individual lifetime. The variability of As metabolism will be further validated using more individuals. There is no doubt that the gut harbors an abundant incredibly diverse microbial community including some bacteria with As resistance genes. Anaerobic members of archaea (methanoarchaea) and bacteria (Bacteroides) isolated from human feces involved in processes that actively volatilize arsenic, other metals and metalloids through methylation and hydrogenation (Meyer et al., 2008; Michalke et al., 2008). The identity of arsenic-metabolizing bacteria isolated from human gut microbiota should be given the great attention, which can further pry the truth of As metabolism in the human gut.

\section{Conclusion}

The present study showed that two individuals gut microbiota had different soil As metabolic potency. The adult gut microbiota displayed the high potency to metabolize As(III) into less toxic methylated species in the colon digests as detoxification; and the methylation rate was two times than that of the child. The child may confront serious health risk, when exposed to large amounts of As(III) with high toxicity in the colon digests. Conservative statistics about 16S rRNA sequencing data showed that at least 20 gut bacteria genera could carry resistance genes of As reduction and methylation. The variability of As metabolism among many individuals need further elucidation. We propose to pay great attention to As biotransformation with homologous enzymes and molecular mechanism in gut metabolism process. This will result in more accurate health risk assessment to different population by orally soil As exposures, and can be as a reference to formulate related risk policies.

\section{Acknowledgements}

This work was supported by the National Natural Science Foundation of China (No. 41271493).

\section{Appendix A. Supplementary data}

Supplementary data related to this article can be found at http:// dx.doi.org/10.1016/j.chemosphere.2017.06.018.

\section{References}

Arumugam, M., et al., 2011. Enterotypes of the human gut microbiome. Nature 473 $174-180$.

Bennett, M.S., et al., 2011. Bacillus subtilis arsenate reductase is structurally and functionally similar to low molecular weight protein tyrosine phosphatases. Proc. Natl. Acad. Sci. U. S. A 98, 13577-13582.

Bowles, A., et al., 2010. Specific aspects of gastro-intestinal transit in children for drug delivery design. Int. J. Pharm. 395, 37-43.

Bradham, K.D., et al., 2011. Relative bioavailability and bioaccessibility and speciation of arsenic in contaminated soils. Environ. Health Perspect. 119, 1629-1634.

Chen, J., et al., 2013. Engineering the soil bacterium Pseudomonas putida for arsenic methylation. Appl. Environ. Microbiol. 79, 4493-4495.

Chen, J., Rosen, B.P., 2016. Organoarsenical biotransformations by Shewanella putrefaciens. Environ. Sci. Technol. 50, 7956-7963.

David, L.A., et al., 2014. Diet rapidly and reproducibly alters the human gut microbiome. Nature 505, 559-563.

Denys, S., et al., 2012. In vivo validation of the unified BARGE method to assess the bioaccessibility of arsenic, antimony, cadmium, and lead in soils. Environ. Sci. Technol. 46, 6252-6260.

Greenblum, S., et al., 2015. Extensive strain-Level copy-number variation across human gut microbiome species. Cell 160, 583-594.

Guo, H.M., et al., 2015. Arsenate reduction and mobilization in the presence of indigenous aerobic bacteria obtained from high arsenic aquifers of the Hetao basin, Inner Mongolia. Environ. Pollut. 203, 50-59.

Hinrichsen, S., et al., 2015. Inorganic and methylated thioarsenates pass the gastrointestinal barrier. Chem. Res. Toxicol. 28, 1678-1680.

Huang, J.H., 2014. Impact of microorganisms on arsenic biogeochemistry: a review. Water Air Soil Pollut. 225, 1848.

Islam, F.S., et al., 2004. Role of metal-reducing bacteria in arsenic release from Bengal delta sediments. Nature 430, 68-71.

Jiang, S., et al., 2013. Differential arsenic mobilization from As-bearing ferrihydrite by iron-respiring Shewanella strains with different arsenic-reducing activities. Environ. Sci. Technol. 47, 8616-8623.

Juhasz, A.L., et al., 2014. Variability associated with as in vivo-in vitro correlations when using different bioaccessibility methodologies. Environ. Sci. Technol. 48, $11646-11653$.

Juhasz, A.L., et al., 2011. Influence of saliva, gastric and intestinal phases on the prediction of as relative bioavailability using the unified Bioaccessibility Research Group of Europe method (UBM). J. Hazard. Mater. 197, 161-168.

Juhasz, A.L., et al., 2015. Predicting arsenic relative bioavailability using multiple in vitro assays: validation of in vivo-in vitro correlations. Environ. Sci. Technol. 48, 11646-11653.

Kubachka, K.M., et al., 2009. In vitro biotransformation of dimethylarsinic acid and trimethylarsine oxide by anaerobic microflora of mouse cecum analyzed by HPLC-ICP-MS and HPLC-ESI-MS. J. Anal. At. Spectrom. 24, 1062-1068.

Laird, B.D., et al., 2007. Gastrointestinal microbes increase arsenic bioaccessibility of ingested mine tailings using the simulator of the human intestinal microbial ecosystem. Environ. Sci. Technol. 41, 5542-5547.

Lin, Y.F., et al., 2006. An arsenic metallochaperone for an arsenic detoxification pump. Proc. Natl. Acad. Sci. U. S. A 103, 15617-15622.

Ljung, K., et al., 2006. Metal and arsenic distribution in soil particle sizes relevant to soil ingestion by children. Appl. Geochem 21, 1613-1624.

Lu, K., et al., 2014. Arsenic exposure perturbs the gut microbiome and its metabolic profile in mice: an integrated metagenomics and metabolomics analysis. Environ. Health Perspect. 122, 284-291.

Meyer, J., et al., 2008. Volatilisation of metals and metalloids: an inherent feature of methanoarchaea? Syst. Appl. Microbiol. 31, 81-87.

Michalke, K., et al., 2008. Role of intestinal microbiota in transformation of bismuth and other metals and metalloids into volatile methyl and hydride derivatives in humans and mice. Appl. Environ. Microbiol. 74, 3069-3075.

Molly, K., et al., 1994. Validation of the simulator of the human intestinal microbial ecosystem (SHIME) reactor using microorganism-associated activities. Microb. Ecol. Health Dis. 7, 191-200.

Muehe, E.M., et al., 2013. Fate of arsenic during microbial reduction of biogenic versus abiogenic As-Fe(III)-mineral coprecipitates. Environ. Sci. Technol. 47, 8297-8307.

Naranmandura, H., et al., 2007. Arsenic metabolism and thioarsenicals in hamsters and rats. Chem. Res. Toxicol. 20, 616-624.

Oremland, R.S., Stolz, J.F., 2003. The ecology of arsenic. Science 300, 939-944.

Oremland, R.S., Stolz, J.F., 2005. Arsenic, microbes and contaminated aquifers. Trends Microbiol. 13, 45-49.

Palmer, C., et al., 2007. Development of the human infant intestinal microbiota. PLoS Biol. 5, 1556-1573.

Qin, J., et al., 2006. Arsenic detoxification and evolution of trimethylarsine gas by a microbial arsenite S-adenosylmethionine methyltransferase. Proc. Natl. Acad. Sci. U. S. A 103, 2075-2080.

Ruby, M.V., et al., 1996. Estimation of lead and arsenic bioavailability using a physiologically based extraction test. Environ. Sci. Technol. 30, 422-430.

Rubin, S.S.C.D., et al., 2014. Arsenic thiolation and the role of sulfate-reducing bacteria from the human intestinal tract. Environ. Health Perspect. 122, $817-822$.

Schlebusch, C.M., et al., 2015. Human adaptation to arsenic-rich environments. Mol. Biol. Evol. 32, 1544-1555.

Stolz, J.E., et al., 2006. Arsenic and selenium in microbial metabolism. Annu. Rev. Microbiol. 60, 107-130.

Sun, G.X., et al., 2012. Arsenic in cooked rice: effect of chemical, enzymatic and microbial processes on bioaccessibility and speciation in the human gastrointestinal tract. Environ. Pollut. 162, 241-246.

Sun, H.J., et al., 2014. Arsenic and selenium toxicity and their interactive effects in humans. Environ. Int. 69, 148-158.

Tian, H.X., et al., 2015. Arsenic biotransformation in solid waste residue: comparison of contributions from bacteria with arsenate and iron reducing pathways. Environ. Sci. Technol. 49, 2140-2146.

Van de Wiele, T., et al., 2010. Arsenic metabolism by human gut microbiota upon in vitro digestion of contaminated soils. Environ. Health Perspect. 118, 1004-1009.

Van den Abbeele, P., et al., 2010. Microbial community development in a dynamic gut model is reproducible, colon region specific, and selective for Bacteroidetes and Clostridium Cluster IX. Appl. Environ. Microbiol. 76, 5237-5246.

Wang, S.L., Mulligan, C.N., 2008. Speciation and surface structure of inorganic arsenic in solid phases: a review. Environ. Int. 34, 867-879.

Wragg, J., et al., 2011. An inter-laboratory trial of the unified BARGE bioaccessibility method for arsenic, cadmium and lead in soil. Sci. Total Environ. 409, 4016-4030.

Wu, Y., et al., 2015. Effect of iron(II) on arsenic sequestration by $\delta-\mathrm{MnO}_{2}$ : desorption 
studies using stirred-flow experiments and X-ray absorption fine structure spectroscopy. Environ. Sci. Technol. 49, 13360-13368.

Yin, N.Y., et al., 2015. An in vitro method to assess soil arsenic metabolism by human gut microbiota: arsenic speciation and distribution. Environ. Sci. Technol. 49, 10675-10681.

Yin, N.Y., et al., 2016. Variability of arsenic bioaccessibility and metabolism in soils by human gut microbiota using different in vitro methods combined with SHIME. Sci. Total Environ. 566, 1670-1677.

Yin, N.Y., et al., 2017. In vitro study of soil arsenic release by human gut microbiota and its intestinal absorption by Caco-2 cells. Chemosphere 168, 358-364.

Ying, S.C., et al., 2011. Competitive microbially and Mn oxide mediated redox processes controlling arsenic speciation and partitioning. Environ. Sci. Technol. 45,
$5572-5579$.

Yu, H.Y. et al., 2016. Arsenic metabolism and toxicity influenced by ferric iron in simulated gastrointestinal tract and the roles of gut microbiota. Environ. Sci. Technol. 50, 7189-7197.

Zhang, J., et al., 2015. Arsenic methylation and volatilization by arsenite S-Adenosylmethionine methyltransferase in Pseudomonas alcaligenes NBRC14159. Appl. Environ. Microbiol. 81, 2852-2860.

Zhu, Y.G., et al., 2014. Earth abides arsenic biotransformations. Annu. Rev. Earth. Pl Sc 42, 443-467.

Zobrist, J., et al., 2000. Mobilization of arsenite by dissimilatory reduction of adsorbed arsenate. Environ. Sci. Technol. 34, 4747-4753. 